\title{
The Necessity of Near-Infrared Protection
}

\section{Yohei Tanaka* and Lisa Gale}

Clinica Tanaka Plastic, Reconstructive Surgery and Anti-aging Center, Matsumoto, Nagano, Japan

Over half of the solar energy consists of near-infrared (NIR), and in addition to natural NIR, humans are continuously exposed to artificial NIR from electrical appliances. A wide range of preventative mechanisms has been evolutionarily maintained in organisms to protect against the effects of NIR [1,2]. Humans have acquired protective mechanisms against NIR on multiple levels, including perspiration, blisters, vasodilation, hair, skin, adipose tissue, and cotton or wool clothing [1].

Previous studies regarding NIR have reported its application in the industrial and agricultural fields, but have not well investigated the effects of NIR exposure in the field of plastic surgery [3]. Although plastic surgeons have not been familiar with the effects of NIR, the potential for NIR effects appears to be high and significant.

We previously elucidated that NIR (1100-1800 nm together with a water-filter that excludes wavelengths $1400-1500 \mathrm{~nm}$ ) non-thermally affects the deeper tissues [1-7]. In addition, we found that NIR is absorbed by water in the skin, hemoglobin in dilated vessels, myoglobin in the superficial muscle, and bone cortical mass, and is scattered by adipose cells [1-5]. The biological effects of NIR have both beneficial applications and deleterious effects [1-5].

NIR can stimulate wound healing [8-10] and treat malignant tumors [11-14]. NIR can also achieve skin rejuvenation and skin tightening [7], induce long-lasting vasodilation that is beneficial for ischemic disorders [3,5], and relax and weaken dystonic and hypertrophic muscles to reduce wrinkles and myalgia [3,5]. In addition to usefulness in cancer detection and imaging, NIR induction of DNA damage in cancer cells should be investigated further for an effective cancer treatment [6]. NIR can also activate stem cells, which may be beneficial in regenerative medicine [3].

However, intensive or long-term exposure to NIR induces deleterious effects similar to UV [1-4]. Various kinds of tissue damage and diseases, such as undesirable photoaging, long-lasting vasodilation, muscle thinning, skin ptosis, sagging, cataracts, and potentially photocarcinogenesis are induced by long-term NIR exposure [4,5]. Despite the wide prevalence of a variety of UV blocking materials, such as sunblock, sunglasses, films, and fibers, effective methods for blocking NIR are not currently established. NIR exhibits both wave and particle properties and is strongly absorbed by water, hemoglobin, and myoglobin [1]. NIR induces photochemical changes and affects a large volume and depth of tissue [15]. As a consequence, NIR can penetrate the skin and the sclera, and affect the deeper tissues, including muscles, lens, and retina, with its high permeability [1-3].

Chronic NIR exposure can induce rosacea, which affects all races, although it is more common in Caucasians and fair-skinned populations [16]. NIR should be considered a critical factor in the development and aggravation of rosacea [3-5].

Erythema ab igne can be induced by long-term exposure to sources of heat and NIR, such as fires and stoves [17], and exhibits histopathological changes similar to those seen in solar-damaged skin [18]. The occurrence of telangiectasia appeared to increase with age, increased sunbathing, and poor pigmentation ability [16]. These lesions may develop thermal keratosis, such as hyperkeratosis, keratinocyte dysplasia, and dermal elastosis, which are similar to the changes that occur in actinically damaged skin [19].

Apoptosis of vascular smooth muscle cells and degeneration of myoglobin are non-thermally induced by NIR, resulting in long-lasting vasodilation $[1,4]$. Muscles are easily damaged by NIR, as they contain hemoglobin and myoglobin [20], which are oxygen-carrying proteins with many hydrogen bonds and alpha helices [1,3-4]. Previous studies have shown that hydrogen bonds and helical structures are resonated by NIR [1,3-4,21]. Thus, it is possible that NIR induces resonance of helical structures in the oxygen-carrying proteins and degenerates proteins containing hydrogen bonds and helical structures, which results in damage to the storage and transport of oxygen [1,4]. This could be one of the mechanisms of apoptosis [1,4]. Humans have biological defense mechanisms in which hydrogen bonds and helical structures are resonated by NIR and absorb NIR to protect subcutaneous tissues against this radiation [1,3-4].

Superficial muscle thinning and the muscle extensions to the dermis are induced by chronic NIR exposure, which ultimately lead to superficial tissue aging and skin ptosis [1,3]. Additional factors thought to contribute to brow ptosis include the gradual loss of forehead skin elasticity and a reduction in the tone of the frontalis muscles [22,23]. The use of NIR treatment for smoothing forehead rhytids also causes brow ptosis $[1,3]$. Compared to darker skin with dense melanin and a thick dermis, fair skin with lower concentrations of melanin and a thin dermis might allow NIR to penetrate deeper into human tissue, and damage superficial muscles, resulting in muscle thinning and skin ptosis [1,3]. Fair skin tends to wrinkle and sag earlier in life [24,25], and characteristics of age-related changes occur at a more accelerated rate in Caucasians [26]. Accordingly, patients with fair skin and a habit of sunbathing tend to seek facelift operations.

Cataract and damages of the retina may be induced by chronic NIR exposure [1-3]. The optic nerve which is the only exposed component of the central nervous system also has defense mechanisms against NIR on multiple levels: rich blood flow in the retina, hyaluronic acid in the lens, tears in sclera, and fat in the eyelid [1-3]. These are effective protective mechanisms, as water, hemoglobin, and fat are all ideal materials for blocking the exposure to and consequences of NIR. NIR is transmitted through the ocular media with little loss of intensity, damaging the retina and contributing to cataracts [27]. Surgeons are intensively exposed to NIR from using the microscope for extended periods of time during microsurgery, thus surgeons should consider protection of eyes from NIR [3].

*Corresponding author: Yohei Tanaka, Clinica Tanaka Plastic, Reconstructive Surgery and Anti-aging Center, Matsumoto, Nagano, Japan, M-1 Bld 1F, 3-4-3, Ote, Matsumoto, Nagano 390-0874, Japan, Tel: +81-263-36-0016; Fax: +81-26336-0016; E-mail: info@clinicatanaka.jp

Received June 20, 2013; Accepted November 22, 2013; Published November 28, 2013

Citation: Tanaka Y, Gale L (2013) The Necessity of Near-Infrared Protection Surgery 3: 150. doi:10.4172/2161-1076.1000150

Copyright: $\odot 2013$ Tanaka Y, et al. This is an open-access article distributed under the terms of the Creative Commons Attribution License, which permits unrestricted use, distribution, and reproduction in any medium, provided the original author and source are credited. 
Carcinomas arise from heat-induced erythema ab igne [2830]. Similar to UV, NIR induces photoaging and potentially photocarcinogenesis [31]. In addition, skin tumors appeared faster after irradiation with the full lamp spectrum containing UV, visible, and NIR compared to irradiation with UV alone [32].

Subcutaneous adipocytes may be induced by NIR to protect the underlying tissues, including the panniculus carnosus in animal and superficial muscles in human, against NIR damage. Subcutaneous adipocytes located above superficial muscles are effective and reasonable for the temperature retention and protection from NIR, because fatty tissue can scatter NIR optically $[3,33]$ and fatty acids are the major NIR absorbing materials in soft tissues [34].

Although various kinds of UV blocking materials are often used to prevent tissue damage from UV exposure, these materials do not block visible light or NIR [1-3]. Therefore, we should protect ourselves with clothing or sunscreen, and glasses that not only block UV, but also $\mathrm{NIR}$, in order to prevent photodamage and photoaging. Additional studies are required to investigate the generally quantified dose limit for the body and the necessity of NIR protection.

\section{References}

1. Tanaka Y, Gale L (2013) Beneficial Applications and Deleterious Effects of Near-infrared From Biological and Medical Points of View. Optics and Photonics Journal 3: 31-39.

2. Tanaka Y, Gale L (2013) The Effect of Near-infrared between 1100-1800 nm together with a Water-filter and a Contact Cooling. Anaplastology 2: 3.

3. Tanaka Y, Tsunemi Y, Kawashima M, Nishida H (2013) The impact of nearinfrared in Plastic Surgery. Plastic Surgery: An International Journal Article ID 973073

4. Tanaka Y (2012) The impact of near-infrared radiation in dermatology. Review. World Journal of Dermatology 1: 30-37.

5. Tanaka Y, Kawashima M (2012) The biological effects of near-infrared. In Japanese. Aesthet Dermatol 22:100-109.

6. Tanaka Y, Tatewaki N, Nishida H, Eitsuka T, Ikekawa N, et al. (2012) Nonthermal DNA damage of cancer cells using near-infrared irradiation. Cancer Sci 103: 1467-1473.

7. Tanaka Y, Tsunemi Y, Kawashima M, Tatewaki N, Nishida H (2013) Objective assessment of skin tightening in Asians using a water-filtered near-infrared $(1,000-1,800 \mathrm{~nm})$ device with contact-cooling and freezer-stored gel. Clin Cosmet Investig Dermatol 6: 167-176.

8. Danno K, Mori N, Toda K, Kobayashi T, Utami A (2001) Near-infrared irradiation stimulates cutaneous wound repair: laboratory experiments on possible mechanisms. Photodermatol Photoimmunol Photomed 17: 261-265.

9. Horwitz LR, Burke TJ, Carnegie D (1999) Augmentation of wound healing using monochromatic infrared energy. Exploration of a new technology for wound management. Adv Wound Care 12: 35-40.

10. Schramm JM, Warner D, Hardesty RA, Oberg KC (2003) A unique combination of infrared and microwave radiation accelerates wound healing. Plast Reconstr Surg 111: 258-266

11. Bäumler W, Abels C, Karrer S, Weiss T, Messmann H, et al. (1999) Photooxidative killing of human colonic cancer cells using indocyanine green and infrared light. Br J Cancer 80: 360-363.

12. Kelleher DK, Thews O, Rzeznik J, Scherz A, Salomon Y, et al. (1999) Waterfiltered infrared-A radiation: a novel technique for localized hyperthermia in combination with bacteriochlorophyll-based photodynamic therapy. Int J Hyperthermia 15: 467-474.

13. Dees C, Harkins J, Petersen MG, Fisher WG, Wachter EA (2002) Treatmen of murine cutaneous melanoma with near infrared light. Photochem Photobio 75: 296-301.

14. Orenstein A, Kostenich G, Kopolovic Y, Babushkina T, Malik Z (1999) Enhancement of ALA-PDT damage by IR-induced hyperthermia on a colon carcinoma model. Photochem Photobiol 69: 703-707
15. Anderson RR, Parrish JA (1981) The optics of human skin. J Invest Dermatol 77: $13-19$.

16. Berg M (1989) Epidemiological studies of the influence of sunlight on the skin Photodermatol 6: 80-84.

17. Finlayson GR, Sams WM Jr, Smith JG Jr (1966) Erythema ab igne: a histopathological study. J Invest Dermatol 46: 104-108.

18. Page EH, Shear NH (1988) Temperature-dependent skin disorders. J Am Acad Dermatol 18: 1003-1019.

19. Arrington JH 3rd, Lockman DS (1979) Thermal keratoses and squamous cell carcinoma in situ associated with erythema ab igne. Arch Dermatol 115: 1226 1228.

20. Srinivasan S, Pogue BW, Jiang S, Dehghani H, Kogel C, et al. (2003) Interpreting hemoglobin and water concentration, oxygen saturation, and scattering measured in vivo by near-infrared breast tomography. Proc Nat Acad Sci U S A 100: 12349-12354.

21. Nevskaya NA, Chirgadze YN (1976) Infrared spectra and resonance interactions of amide-I and II vibration of alpha-helix. Biopolymers 15: 637-648.

22. Knize DM (1996) An anatomically based study of the mechanism of eyebrow ptosis. Plast Reconstr Surg 97: 1321-1333.

23. Niechajev I (2004) Transpalpebral browpexy. Plast Reconstr Surg 113: 2172 2180.

24. Rawlings AV (2006) Ethnic skin types: are there differences in skin structure and function? Int J Cosmet Sci 28: 79-93.

25. Tsukahara K, Fujimura T, Yoshida Y, Kitahara T, Hotta M, et al. (2004) Comparison of age-related changes in wrinkling and sagging of the skin in Caucasian females and in Japanese females. J Cosmet Sci 55: 351-371.

26. Odunze M, Rosenberg DS, Few JW (2008) Periorbital aging and ethnic considerations: a focus on the lateral canthal complex. Plast Reconstr Surg 121: $1002-1008$

27. Niemz MH (2007) Laser-tissue interactions fundamentals and applications.

28. Hewitt JB, Sherif A, Kerr KM, Stankler L (1993) Merkel cell and squamous cell carcinomas arising in erythema ab igne. $\mathrm{Br} \mathrm{J}$ Dermatol 128: 591-592.

29. Jones CS, Tyring SK, Lee PC, Fine JD (1988) Development of neuroendocrine (Merkel cell) carcinoma mixed with squamous cell carcinoma in erythema ab igne. Arch Dermatol 124: 110-113.

30. Kligman LH (1982) Intensification of ultraviolet-induced dermal damage by infrared radiation. Arch Dermatol Res 272: 229-238.

31. Schieke SM, Schroeder P, Krutmann J (2003) Cutaneous effects of infrared radiation: from clinical observations to molecular response mechanisms. Photodermatol Photoimmunol Photomed 19: 228-234.

32. Bain JA, Rusch HP, Kline BE (1943) The effect of temperature upon ultraviolet carcinogenesis with wavelength $2,800-3,400 A^{\circ}$. Cancer Res 3: 610-612.

33. van Veen RL, Sterenborg HJ, Pifferi A, Torricelli A, Chikoidze E, et al. (2005) Determination of visible near-IR absorption coefficients of mammalian fat using time- and spatially resolved diffuse reflectance and transmission spectroscopy. J Biomed Opt 10: 054004.

34. Tsai $\mathrm{CH}$, Chen JC, Wang WJ (2001) Near-infrared absorption property of biological soft tissue constituents. J Med Biol Eng 21:7-14.

This article was originally published in a special issue, Plastic Surgery handled by Editor(s). Dr. Eduardo Krulig, Centro Medico, Spain 